Success and failure in integrated models of nursing for long term conditions: multiple case studies of whole systems

Susan Procter PhD, BSc, RN

Professor of Clinical Nursing Practice and Innovation

Buckinghamshire New University, UK

Imperial College Healthcare NHS Trust, UK

s.procter@bucks.ac.uk

Patricia Mary Wilson PhD, RN, NDN

Senior Clinical Research Fellow

University of Hertfordshire, UK

Fiona Brooks PhD

Professor of Health Services Research

University of Hertfordshire, UK

Sally Kendall PhD, RN, RHV

Professor of Nursing

University of Hertfordshire, UK 


\section{Acknowledgements to key contributors}

The authors would like to acknowledge Elaine McNeilly, Jo Magnusson, Melissa Chamney, Sally Roberts and Stephen Abbott who contributed to data collection and analysis at various stages of the PEARLE project.

\section{HS\&DR Funding Acknowledgement}

This project was funded by the National Institute for Health Research Health Services \& Delivery Research Programme (project number 08/1605/121).

\section{Department of Health Disclaimer}

The views and opinions expressed therein are those of the authors and do not necessarily reflect those of the HS\&DR Programme, NIHR, NHS or the Department of Health. 


\section{Abstract}

Background: Current projections indicate that the UK faces a $252 \%$ increase in people aged over 65 with one or more long term conditions (LTC) by 2050 . Nurses, managing their own caseloads and clinics, working across sectors and organisational boundaries and as part of a wider multi-disciplinary team, are frequently seen as key to managing this growing demand. However, the evidence base informing the nursing role in managing LTC, the most effective configuration of the multi-disciplinary team and the policy evidence relating to the infrastructure required to support cross organisational working, remains weak.

Objectives: To explore, identify and characterise the origins, processes and outcomes of effective chronic disease management models and the nursing contributions to such models.

Design: Case study whole systems analysis using qualitative interview methods.

Settings: Two community matron services, two primary care (GP) practice nursing services, two hospital based specialist nursing services were purposefully sampled from across England and Wales.

Participants: Selection criteria were derived using a consensus conference. The nurses in the service, all patients and carers on the caseload, members of the multidisciplinary team and stakeholders were invited to participate.

Methods: Semi-structured interviews with all participants, thematic analysis within a whole system framework. 
Results: The study found high levels of clinical nursing expertise which in the case of the community matrons was meeting the aim of reducing hospital admissions. Both the primary care and hospital nurse specialist indicate similar levels of clinical expertise which was highly valued by medical colleagues and patients. Patients continued to experience fragmented care determined by diagnostic categories rather than patient need and by the specific remit of the clinic or service the patient was using. Patient data systems are still organised around the impact on services and prevalence of disease at an individual level and not around the patient experience of disease.

Conclusion: Nurses are making a major contribution to meeting the policy objectives for long term conditions. Primary care nurses and hospital nurse specialists do broadly similar roles. The scope of the nursing roles and services studied were idiosyncratic, opportunistic and reactive, rather than planned and commissioned on an analysis of local population need.

\section{Key words}

Case study, chronic care model, chronic disease management, community matron, long term conditions, nurse specialists, primary care nursing, whole systems analysis 
What is already known about the topic?

- Reducing mortality from chronic illness and maintaining health among those experiencing long term conditions requires health care professional engagement with lifestyle factors, interventions to support self-care and the acquisition of genuine patient expertise encompassed in the long term conditions model of care.

- The majority of people with long term conditions are able to self-care with carefully targeted professional input.

- There is evidence of improved outcomes from enhancing nurse leadership and nurse led case management.

- The transfer of nurse-led models of care developed in different health policy contexts, particularly the US, into the UK setting, has not replicated the patient outcomes demonstrated elsewhere.

- The evidence base informing the nursing role in managing long term conditions, the most effective configuration of the multi-disciplinary team and the policy evidence relating to the infrastructure required to implement the long term conditions model of care, remains weak.

What this paper adds?

- The study identifies shared features of the expertise and behaviours of primary care nurses, hospital based nurse specialists and community matrons in enabling effective self-management support for patients with long term conditions.

- Hospital nurse specialist and primary care nursing service models evolved organically interfacing locally with disease orientated systems underpinned by 
evidence based medicine as exemplified in nationally endorsed guidelines, service frameworks and the Quality Outcomes Framework (which governs the quality and funding of primary care services in the UK). Collectively these create a web of structural relationships which hamper the development of nursing roles to respond effectively to the needs of patients with long term conditions.

- The structural determinants of the community matron role are rooted in the principles of long term condition care models derived from a predominately US evidence base using principles of population stratification. Community matrons demonstrated many of the behaviours identified to be supportive of the long term conditions model of care. However, community matrons had to work hard to establish their legitimacy in the local health community and lacked championship by powerful professional colleagues.

- Despite exemplary clinical expertise on the part of the nursing services, the experience of patients with a range of different conditions was remarkably similar and remains rooted in a disease orientated, fragmented model of care. Changing care models to meet the needs of patients with long term conditions requires a systemic rather than individualistic approach to service development. 


\section{Introduction}

This paper provides an analysis of the contribution nurses make to the implementation of the aims of the UK Department of Health Long Term Conditions (LTC) strategy (Department of Health, 2005a). Current projections indicate that the UK faces a $252 \%$ increase in people aged over 65 with one or more LTCs by 2050 (Department of Health 2011). Effective management of LTCs challenges many of the assumptions that underpin a disease orientated model of care dominant in western health care delivery systems (Department of Health 2004a, Harwood et al. 2004, Ham and Oldham 2009). Reducing mortality from chronic illness and maintaining health among those experiencing LTCs requires engagement with lifestyle factors (Wanless 2002) and the acquisition of genuine patient expertise (Thorne 2008). This is difficult to address in acute care settings which are characterised by disease orientated, episodic and time limited engagement with the patient, focused on early discharge back into the community.

Evidence indicates improved outcomes from enhancing nurse leadership (Bodenheimer et al. 2005) and nurse led case management (Sergeant et al. 2007). There is evidence that people with LTCs are able to self-care with carefully targeted professional input (Berzins et al. 2009). A range of US models piloted within the UK such as Kaiser Permanente and Pursuing Perfection (Department of Health, 2004b) and the Expert Patient Programme (Rogers et al. 2006, Wilson 2008) have the facilitation of patient self-management as a key aim (Department of Health 2001, 2005b). Many of the UK initiatives build on evidence of the effective management of LTCs pioneered in the US (Wagner 1998, Boaden 2006, Wagner and Groves 2002, Department of Health 2005b, 2008). Nurses, managing their own caseloads and clinics, working across sectors and organisational boundaries and as part of a wider 
multi-disciplinary team, are frequently seen as key to managing increasing demand (Bodenheimer et al. 2005, Department of Health 2005a, 2008). However, the transfer of nurse-led models developed in different health policy contexts, particularly the US, into the UK setting has not replicated the patient outcomes demonstrated elsewhere (Boaden 2006, Wilson et al. 2006, Gravelle et al. 2007). The evidence base informing the nursing role in managing LTC, the most effective configuration of the multi-disciplinary team and the policy evidence relating to the infrastructure required to support cross organisational working, remains weak (McHugh et al. 2009).

\section{Aim of study}

The PEARLE study (Prevention, Enabling Self Care and cARe in Long Term Conditions Evaluation) aimed to explore, identify and characterise the origins, processes and outcomes of effective chronic disease management models and the nursing contributions to such models.

\section{Methodology}

Results from the PEARLE study specifically relating to public perception of the nurse's role in long term conditions are reported elsewhere (Wilson et al. 2012). The findings presented here are taken from an analysis of six case study sites (see Table 1) representing three of the four delivery systems for LTC identified by the UK Department of Health (2005a), these are shown in Fig 1.

Insert Fig One here 
Insert Table One here

The research used evaluative case study design (Yin 2003a) with the unit of analysis defined as the LTC nurses caseload linked to the multi-disciplinary team where necessary (Kendall et al. 2010). In undertaking the research there was a need to build explanations as to why the LTC model may have more impact in one case than another or for a certain cohort of patients, e.g. frail elderly. Thus, within the typology of case study approaches proposed within the literature (Marinetto, 1999; Yin, 2003a; Yin, 2003b), the most appropriate method for reviewing the effectiveness of service provision is argued to be the 'explanatory case study' (Yin, 2003b).

Explanation is guided through key theoretical propositions and demonstrated through narrative. The use of an iterative, comparative data process ensures that a final explanatory model can be arrived at (Marinetto, 1999).

In undertaking this analysis key theoretical propositions derived from national and international policies designed to improve the management of LTCs were used to frame the analysis of the case study data in order to identify the processes of implementation and the variations and permutations of intention that occur during these processes (Carey 2010). To aid transparency in the process of data analysis the case study data were categorised using a whole systems framework. A whole systems framework was selected as the principles of whole system working permeate current policy agendas in relation to LTC (Ham and Oldham 2009). There are a variety of approaches to whole system analysis (Department of Health 2005c, Browne et al. 2007). The approach used here is based on the work of Kendrick and Conway (2003) who developed a whole system model to analyse delayed hospital discharge in Scotland. They identified four principal perspectives in producing a whole systems analysis: 
i) The organisational whole system is by far the most common context in which whole systems are analysed. The emphasis is on making the various parts of the health and social care system function together as a single system rather than as parallel systems.

ii) The patient experience of the whole system recognises that the whole system comes together and is embodied in the experience of each individual patient. The individual experience, therefore, provides a microcosm of the level of service integration achieved locally and provides evidence of model outcomes.

iii) The data system recognises that for many of the most important areas of the whole system there is very little data and this influences understanding of the causal factors determining outcomes.

iv)The causal system is a network of causal relationships which shifts attention away from daily surface events towards the unfolding of slow gradual structural processes over time, which Senge (1990) identifies as key in determining the outcomes of change.

\section{Case study selection}

Expert nurses working within the field of LTC were identified via a systematic search of UK practice focused journals and websites. Details of the sampling process are given in a previous article (Wilson et al. 2012).

Seven case studies were identified that included models encompassed in the longterm conditions model (Department of Health, 2005a) (see Fig 1) and ranged across the severe end of the LTC spectrum including co-morbidity through to the selfcaring/management level of provision. A public health case study representing secondary prevention of asthma in children and young people will be reported elsewhere. The case study models reported here represented nursing contributions 
to LTC in primary, secondary and intermediate care settings for adult patients. Data were collected during $2007 / 8$. Ethics approval was gained for the study through the NHS National Research Ethics Service and local NHS research governance departments, written informed consent was obtained from each participant.

\section{Data collection}

Data collection at each site consisted of semi-structured audio recorded face to face or telephone interviews of between 30 minutes to one hour, with members of the multi-disciplinary team, patients, their carers, managers and commissioners (see Table 1) and documentary analysis of local policies. Snowball sampling was used to identify the participants. Patients and carers were recruited by the local nursing team and referred to the research team if they were interested in participating. In each case study site the number of participants recruited was justified by the degree of saturation that was being reached through the interview process (Kuper et al. 2008). Details of each case study site are provided in Wilson et al. (2012) and are summarised below.

\section{Data analysis}

Data analysis was guided by the whole system perspective described above and designed to address the specific contribution made by nursing to strategic models of chronic disease management. An overview of the data collected at each site is given in Table 1. Data were analysed using Nvivo. All authors were involved in data collection and analysis as means of aiding the reliability of the coding. 
Data analysis was undertaken by classifying the data within each case study thematically (Boyatizis, 1998). Key themes from each case study were then mapped into the whole system analysis to enable a comparative description of the cases. Finally, the UK policy objectives for LTC were applied to the four principle perspectives used in the whole systems analysis to enable a theoretical interpretation of the comparative differences between case studies identified during the whole system analysis.

\section{Primary nursing care (PNC) case studies}

PNC1: Based in Wales and centred around the management of diabetes across a General Practice (GP) population by the practice nurse. The practice is situated within a Local Health Board serving a predominantly white population of about 91,000 with a slightly above average population aged 85 and over. The practice nurse ran a weekly diabetes clinic (eight hours) managing the care of the majority of patients with Type 2 diabetes registered at the practice. GP support, practice administrative and electronic data management support were available. Sessional dietetics and podiatry were provided. Retinal screening was provided by an all-Wales programme administered using local opticians.

PNC2: Based in the East Midlands involving practice nurses within one GP practice working across a range of long-term conditions. The practice nursing team comprised of 3 qualified nurses ( 1 nurse practitioner and 2 practice nurses) and 1 Health Care Assistant (HCA). The nurses manage 4 chronic conditions; chronic obstructive pulmonary disease (COPD) and asthma which have discrete clinics led by the nurse practitioner, coronary heart disease (CHD) which has a discrete clinic led by one of 
the practice nurses, and diabetes which is managed in generic clinics covered by any of the nurses. GP, phlebotomist, administrative and electronic data management support were available. The GP practice is located in a Local Authority area with a population 111,000 a below average proportion of people from ethnic minority groups and slightly above average proportion of people aged 15-64.

These case studies focused on the practice populations covered by the nursing service in each practice. Both services started in the early 1990s.

\section{Nurse specialist (NS) case studies}

NS1: Based in a hospital in the East Midlands and centred on nurse led management of patients with epilepsy covering a predominantly white urban population of approximately 360,000 .

The Epilepsy Specialist Nurse (ESN) worked highly autonomously in collaboration with a consultant neurologist to support people with epilepsy. She carried a caseload and undertook about 25 patient consultations a week. The ESN links with the consultant neurologist, learning disabilities team, practice nurses and GPs, school nurses and the community nursing service.

The ESN took up post in the late 1990's at the same time as the consultant neurologist with whom she worked very closely.

NS2: Based in a hospital in the South East Midlands and centred on a large multiprofessional diabetes service covering an urban and rural population of approximately 934,000 with more than one third of the population from black and minority ethic groups. The Nurse Consultant for Diabetes is supported by a large team of Diabetes Nurse Specialists who rotate through in-patient care, outpatient care and primary care. 
The Nurse Consultant was part of a Physician led large multi-disciplinary team providing comprehensive diabetes care. The service is supported by and in turn supports a large diabetes research centre which undertakes a wide range of clinical and evaluative research.

The hospital team includes doctors, nurses, allied health professionals, researchers and dedicated administrative support working in partnership with primary care. The origins of the hospital based diabetes service go back three generations of practitioners to the 1940 s and 1950s.

\section{Community matron (CM) case studies}

CM1: Based in a Primary Care Trust (PCT - providing community nursing services) in the West Midlands servicing a population of approximately 220,000 with a proportionately low ethnic minority population. At the time of data collection the PCT responsible for the original case study was merging with two other PCTs and three very different community matron services were amalgamating. Consequently the teams were in a state of transition and data collection from health professionals was not feasible.

CM2: Based in a PCT in inner London serving a population of 215,000 over $50 \%$ of whom are from black and ethnic minority communities. Case management of patients with LTC who met the inclusion criteria for the service including; the patient having two or more LTCs, a complex drug regimen (polypharmacy), had visited the emergency department twice or more or had had two or more unplanned hospital admissions in the past twelve months, made frequent visits or call outs of the GP, and were not already under the care of a condition specific nurse specialist.

The case study consisted of four community matrons, each had a caseload of approximately 50 patients. The Community Matrons had developed the skills and 
competencies described in the education framework (Department of Health 2006). No interview data were collected from the patients and carers as they were considered to be too frail to take part in the interviews.

In both sites community matrons worked alongside and interchangeably with other professionals including those from social care. Both services were relatively new triggered by top-down initiatives from the Department of Health (2005a).

\section{Findings}

The findings are presented using the whole system framework described above linked to an analysis of UK strategic policy directives for LTC (Department of Health 2005a).

\section{Organisational whole system}

- To embed into local health and social care communities an effective, systematic approach to the care and management of patients with a long term condition (Department of Health 2005a).

There was evidence that nurses were working across primary, secondary and social care boundaries. Nurses in NS2 work on the hospital wards but also circulate to outpatients and primary care clinics. The service has pioneered and evaluated a wide range of diabetic educational programmes including DESMOND (Diabetes Education and Self Management for Ongoing and Newly Diagnosed) and DAFNE (Dose Adjustment for Normal Eating) Programmes (DAFNE study Group 2002) and Expert 
Patient Programmes (Department of Health, 2001). These are mainly delivered in community care settings. The NS1 team is much smaller but the nurse specialist also works within a larger multi-disciplinary team frequently working out into primary care:

'...she [ESN] does go around the health centres as well and see the treatment room staff just to give them information and support them as well. Because people [with epilepsy] just sort of appear, don't they, in front of them, the treatment room sisters. So she's got a good link with them as well.' NS1 nurse 3

Community matrons in CM2 described how in the early days of their service there were many problems with referrals to social care including the need to complete lengthy forms and a significant waiting time until a social assessment was made. However, most of these problems have since been resolved:

'I've got a patient that lives alone, has no family, no food, the last time I went in there, I saw him eating a pack of crisps and he's got cancer. I was so shocked, he has nothing but bread, nothing in the house and then immediately I phoned the Social Services and said that I need meals-on-wheels to start immediately. And that without them asking me to fill all these forms, he's got the service, there's the option that we start the service, essential we get food this afternoon and we can do the referral tomorrow.' CM2 Community Matron 2

These data indicate growing cooperation at a grassroots level, but they do not evidence an effective and systematic approach to the care and management of patients with a LTC. 
- To reduce the reliance on secondary care services and increase the provision of care in a primary, community or home environment (Department of Health 2005a).

Evidence in relation to this policy objective was mixed and difficult to disaggregate as the modes of service delivery provided by nurses frequently spanned primary and secondary care provision. Evidence was most apparent in the community matron services where their input was described as varying between intensive during acute exacerbations of an underlying condition, with less frequent visits at other times for maintenance:

'... when I was bad this last time, she [CM] said "we'll try this so you don't have to go into hospital" didn't she? She decided on the nebuliser and the oxygen.' CM1F01

'But definitely from the phone calls that the Community Matrons receive, people, clients are starting to phone them rather than a hospital or the ambulance.' CM2 Adult community nursing manager

There was some evidence that primary care nurses also reduced reliance on secondary care services:

'Apart from seeing the [practice] nurses, I mean I've not had to see the specialist [hospital medical consultant] again in that time.' PCN2M01

And that both primary care nurses and nurse specialists were considered as clinical experts in specific areas of care provision: 
'[She] [practice nurse] has become essentially a mini GP in diabetes within the surgery. She's been able to provide the experience, the expertise and the continuity' PCN1 GP

'I think she [ESN] takes on enormous responsibility which is... I mean she is very experienced and she is actually extremely able .....I mean she's the Consultant for Epilepsy in this area really.' NS1 GP

Hospital nurse specialists were viewed as very knowledgeable by patients:

' I do think they [nurse specialists] are very knowledgeable.... when I have problems in terms of tweaking my insulin or anything around that, they offer a solution to me.' NS2F04

'...you know you look at her [ESN] for more the expert...she's more in tune with it really. I mean all my doctor's going to do is send me to her. So you're just cutting out the middle man really.' NS1M04

However, both primary care nurses and nurse specialists tended to provide routine support through nurse run clinics:

'You know I get regularly checked with our practice nurse and she's brilliant, so you've got your feet, you've got everything, your weight.' PCN1F08

'It's mainly for the BP that I go to see $x x x x$ [Practice Nurse] and for my yearly... my birthday check-up as they call it'. PCN2M07

'You sit outside on a little chair, go into one room and then move down and go into another. .. normally a lady checks my blood, checks my weight, takes my urine and then I go and have my bloods done and I get taken into another little room and I have my BP checked, my feet checked, all my sites of where 
I inject myself checked... then I go and see my specialist nurse. Usually there is a dietician there as well...' NS2FO1

There was very little evidence to support proactive approaches to reducing reliance on hospital services by primary care nurses. In both primary care case studies most type 1 diabetic patients were managed exclusively by the hospital with little or no input from primary care.

Interviewer 'So you don't see the Diabetes Nurse attached to the practice?' ... 'I don't, well because no-one's offered, no-one's offered it'. PCN1F03

With hospital nurse specialists replicating the key features of the primary care nursing role as illustrated in the following responses from patients on primary care caseloads:

Interviewer 'So it wasn't the one [practice nurse] attached to the surgery?' 'No, no the one from [Town x] Hospital came for the first week was it?...Every day, showed me how to do the injections and all that sort of thing and she also started the injections off at a certain level and then she would come the next day, check my sugar levels and then based on that and in consultation with [Diabetic Consultant] she would either raise or lower the dose either way, raised it was and she'd have got the right level and when she got the right level, balance they call it, then that's what you stick with.' PCN1M06

'I went on a really excellent course at the hospital ....... where we were taught how to sort of read our blood sugars and understand what's going on and 
trying to work out how to work out the proper dosages and so on. It was a good course.' PCN1F03

Where care was shared between primary and hospital care this could cause duplication for patients:

'I'm under control of four people if you like, my GP, my practice nurse, specialist diabetic nurse, and the specialist diabetic (hospital) doctor. So I get controlled by four people and what I'm advised to do.' PCN1M02

Interviewer '... what contact do you have then with the Practice Nurse with regard to your diabetes?'

'I did go through... she [Practice Nurse] did assess me last year mainly because I had a foot ulcer and she thought it necessary but I've always tried to avoid that actually because I'm being seen to at the hospital. I don't see why I've got to go and have two lots of tests within perhaps a month for the same results. So I'd prefer to go to the hospital.' PCN1M09

Patients particularly in primary care identified a lack of access to nurses outside of 9 to 5 weekdays with contact being primarily available through clinic appointments:

Interviewer 'But you wouldn't contact the nurses in the first instance?'

'Well you can't really'. PCN2MO3

'but that nurse is brilliant, but she only ever works one day a week, which I think is absolutely ridiculous, you know. And I did ask receptionist, can you get in touch with her, but you can't really, you've got to ring and if she's there, 
only there on Thursday, if she's there and hasn't got a patient then you can talk to her. But if she's got a patient you can't.' PCN1M04

Nurse specialists had managed to overcome this:

'The second time I saw her [ESN], I felt so at ease with her, I felt like I could ring her rather than bothering the GP. I felt I would get a quicker response from her anyway than the GP.' NS1F05

'...they were lovely... I mean, she was very sympathetic and very conscious of the fact I was quite young to get it [diabetes] and it was quite a big shock for me. She gave me her home phone number as well which I know now was a real extra thing, you know, because I was so worried about it. She said if ever I needed anything to give her a ring. ' NS2F02

Data from all six case studies indicate high levels of clinical expertise which in the case of the community matrons was meeting the aim of reducing hospital admissions. Both the primary care and hospital nurse specialist case studies indicate similar levels of nurse expertise which was highly valued by medical colleagues and patients.

\section{The patient experience}

- Patients with long term conditions need high-quality care personalized to meet their individual requirements (Department of Health 2005a). 
There was plenty of evidence to demonstrate that nurses provided personalised care responsive to the individual needs of patients, some of which is described above. Primary care nursing was able to individualise care:

'They're good, I mean because I'm on a load of aspirin obviously, I bleed forever and if I cut myself in the day I just phone up and say "I've just managed to cut myself" she [Practice Nurse] said "can you be here within an hour?" I said "yeah" she said "right, come up" and they sort it out you know'. PNC1M02.

While community matrons varied the level of care they provided depending on the patients condition:

'We don't call him [GP] do we now... we don't go up there very often other than if she's due for a blood test or something like that or if she's really ill or if she's fixed something up. I mean this illness she's just had is sort of ongoing, it's if she gets an infection in her chest or whatever then the sputum starts, her chest gets tight so then she goes on these, we've got to the stage where we can start her off on these antibiotics, then I ring [CM] and she'll come in and then if she thinks it's an ongoing thing she'll come in every day or every other day or whatever and we just leave it to her.'

Interviewer '...would she [CM] always be your first port of call?'

'Oh yes.' CM1 Carer F01

Often providing personalized care requires negotiation between health care professionals or across service boundaries, under these circumstances this aim can become problematic: 
'There have been occasions when I go to hospital and I have really fought with the staff, you know I said can you put my number on the computer beside this patient and phone me when this patient is coming home ... but you still don't get that.' CM2 Community matron 3

'The community matrons are doing an amazing job at engaging with individual GPs who may have been fairly dubious about the role, and have got some lovely anecdotal stories about us, you know GPs who initially wouldn't barely even talk to them about it, and then, now ringing them up and say "you've got to come and see this lady", you know and this sort of thing, so that's really good to hear.' CM2 stakeholder 2

The majority of the patients interviewed using community matron and primary care services suffered from one or more additional conditions and reflected the problems of co-and multi-morbidity which characterises the aging of the population (Starfield 2011). The impact on the patients' health and quality of life, of each diagnosis, varied. In each case there was usually one overriding diagnosis that was causing the patient the most problems, this wasn't necessarily the most serious (life shortening) diagnosis neither did it necessarily coincide with the clinics organised by the practice nurses:

'Well I suppose I've got sugar diabetes, high BP, glaucoma, arthritis, is that the lot? Yeah, I think so...'

Interviewer 'Which condition concerns you the most?'

'The arthritis really.' PCN2F03

In primary care, care for patients tended to be compartmentalised according to the organisation of services: 
'So it's monthly for your weight and it's six monthly for your BP, your bloods and they check your urine. And then it's yearly you have to go to the hospital to have your eyes done.' PCN2 Carer M01

'My COPD is only ever checked when it needs to be checked. Even if I go to the COPD nurse for my [three monthly vitamin B12] injection and she has to get my injection and she'll say to me "are you okay". So it's not often my COPD is talked about unless I raise the issue or I'm actually at a COPD appointment.' PCN2F01

Patients reported that each disease was treated separately and the integration of disease management that constituted their everyday experience was something they had to work out for themselves and generally went unrecognised by all the practitioners they visited:

'I already said, I can't do the exercise you know, just a catch twenty-two position, I mean the doctor said to me, "So we've got to keep, watch your weight because it'll affect the diabetes," but what they don't seem to understand is that if you, if you've got the claudication you can't do exercises anyway which means you'll have a job to reduce weight if you don't do exercises.' PCN1M06

The disease orientated role of the primary care nursing service was evidenced in descriptions of their role given by colleagues:

'So when patients are referred to her [primary nurse], she coordinates the annual review and the routine review of patients with diabetes. She ensures that their bloods are taken and gets everything checked off to make sure that they've been referred to the Retinopathy Screening Service, they've been seen by the Dietician and the Podiatrist for their annual assessment and goes through a medication 
review and a blood test review with the patient.' Local Health Board diabetes specialist nurse

While living everyday with co- and multi-morbidity and learning how to balance selfcare management of their diseases, patients had to compartmentalise their experience into specific disease categories when visiting a practitioner, whether it was a nurse, GP or medical consultant.

'... every time I go and see the doctor, he very seldom mentions to me the diabetes. Obviously because there is no problem with it, but he is always concerned about the blood pressure.' PCN1M04

The data indicate a limited approach to personalised care, particularly for patients living with more than one LTC, that was often determined by diagnostic categories rather than by patient need and by the specific remit of the clinic or service the patient was using. The overriding patient need was for integrated, personalized care that can address their particular spectrum of multiple pathologies and the patient's personal priorities. Specialisation in knowledge and services has created formidable obstacles to addressing these complex needs. This is further reinforced by the Quality Outcomes Framework (QOF) (Department of Health 2004b) which remunerates GP services for achieving disease specific targets and was consistently cited as a rationale for establishing the nursing clinics:

'I think it [diabetes nurse clinic] was generated partly out of a desire to extend the nursing role. To initially answer some of the things that were coming out of National Service Frameworks and trying to set up better clinics while protecting doctor time to deal with those sort of problems. Then 
eventually, yes, QOF came along so they had to be developed further.' PCN2 GP1

\section{Data systems}

The integration of clinical data systems has been identified as a key requirement for chronic disease management (Bodenheimer et al. 2002). Evidence from this study indicates that data systems are still organised around the impact on services and prevalence of disease at an individual level and not around the patient experience of disease:

'I haven't got the data here in front of me but you know one thing we did have to do is capture hospital avoidance ... but we can actually look at the individual cases and we've captured that, you know how it's reduced the sort of visits to GP practices, to the hospital.' CM2 stakeholder 1

In both primary care case studies GP practices retained good patient registers patients were recalled for their annual reviews and six monthly checks and were able to make appointments between these visits if required:

'we're seen twice a year [by the Practice Nurse]" PCN1F08

'and they've got a general practitioner nurse which when I'm mobile, I see her every three months because they keep a regular check on my blood pressure." PCN2MO2

There was evidence that within GP practices patient information was integrated: 
'they've got different nurses because everything's computerised, they just bring it up on the computer, who you are, all the medication I take, when I last went so they have a full record there for anyone I see.' PCN2M07

But that these systems did not integrate well with other services:

'...Because the District Nurses were at that time based within the practice and now they've moved to a different location. So it's difficult if we've got a patient who needs to be seen at home and is being seen by the District Nurses because they would say "well, we'll do their diabetic check" but we weren't getting the information. So in the end we've had to more or less abandon that and not use them as regards, you know maintaining our patient contact on an annual basis. So now what happens is [practice nurse 2] does go out and do home visits ......because that way the information was being put on the system in order to meet the QOF requirements.' PCN2 Nurse3

The community matrons had the most explicit data system set up as their role commenced. The main purpose of the data system was to case find and to track hospital admissions. In CM1 data were routinely collected on age, gender, predominating condition, polypharmacy, outcomes, BP and FEV1 (Forced Expiratory volume in one second) measurements. There was a continued reliance on paper sourced data, with folders kept in patients' homes in which all professionals had a section to complete at each visit. Patients and relatives were discouraged from contributing to these notes and there was a separate 'conversation book' used for written communication between the community matrons and any informal carers. In CM2 issues with accessing systems used by the GPs were problematic: 
'...the challenge is the time we spent running around from one GP practice to another and you know trying to input, at least for the GP to know what you've been doing officially with it to prescribe medication, you need to let them know so running from one GP to another it takes a lot of time.' CM2 Community matron 3

At the time of data collection it appeared that many of these issues would be resolved by being part of the EMIS web project (Egton Medical Information Systems 2011) which creates a single system connecting GP practices, community matrons, community nursing and the Primary Care organisation. The EMIS web also includes a "flagging up" system for the emergency department and out of hour's service indicating that the patient was being case managed.

Clinical information was not routinely collected in NS1. Patient records were written by hand during the consultation, routine recording of blood pressure or other clinical data was not undertaken. Although the nurse specialist was provided with a computer, her clinics were held in other department's consulting rooms where there was no access to computing facilities:

'IT [information technology] is very good, we've all got our own PC's [personal computers], desk PC application. But in clinic it's more difficult because you don't necessarily have access to even a telephone or a PC in the actual clinic situation. I mean in hospitals they tend not to use the PC's quite so much but I suppose if you wanted to look at results it's just not available.' NS1 Nurse 2

In contrast in NS2 a clinical monitoring system had been established in 1997 and was managed by a full-time administrator. This recorded all diabetes data including blood sugar, blood pressure, height and weight. Data were entered during the consultation and the patient was provided with a letter with all the results and suggestions for ways of improving control at the end of the appointment. 
'I get a letter very, very promptly, usually within the space of a couple of weeks. From my review I get all my results. A copy also goes to my GP and I actually get the same copy as my GP gets. Every single time that I have an appointment, whether it's with a nurse or whether it's the dietician or at my review, I do get information. It's just literally like a review and recap of what was discussed anyway but, yes, I always get something in writing from them.' NS2F01

The system was available for use remotely at satellite clinics and recorded comorbidities. Data could be translated into graphs which were often used as a patient teaching aid. The system also incorporated an email facility which was used by the various clinicians to communicate, and a journal where any hospital admissions and progress was recorded. The system was overseen by the Consultant Head of Service and any issues were addressed at the bi-monthly clinical governance meetings. Data produced by the system were also drawn on for research purposes. However, the system used at the case study hospital was different to the one used at the other hospital in the same city and it seemed impossible to link the systems over the entire diabetes service. If a patient received care at both hospitals then they would be entered on both systems separately.

\section{Causal system}

The data indicate that specialist nurses were particularly proactive in patient management and patients had good access when they needed it. Where patients are receiving nurse-led primary care for a specified chronic disease for which specialist primary care nurses and/or clinics are available there is evidence that the care is well managed, informed and preventative. Patients value the nursing input and are able to understand and use the services effectively. Exceptionally patients can self refer 
into primary care nurse led clinics. It is still the case, however, that patients contacting GP practices outside of their routine clinic appointments are likely to see a GP rather than a nurse, even if the trigger for the contact is the condition being managed via the nurse led clinic.

The causal model underpinning the nurse specialist services and the primary care nursing services reflects a disease orientated system underpinned by evidence based medicine exemplified by nationally endorsed guidelines and service frameworks. Sustainability is significantly dependent on the championship and protectionism offered by senior medical clinicians. These models are further sustained by epidemiological imperatives such as the rise in diabetes prevalence and Department of Health policy responses. A focus on self-management in LTCs gives particular impetus to nurse run enablement of self-management programmes. Collectively these constitute a web of causal structural relationships which in turn are significantly reinforced in primary care by the QOF framework which governs the quality and funding of primary care services in the UK.

The community matron role did not evolve in the same way as the other models within this research. The causal determinants of the community matron model is rooted in the principles of LTC care derived from a predominately US evidence base (Kane et al. 2003) applying principles of population stratification developed by Kaiser Permanente (Grange 2011) and was implemented using a top-down Department of Health led approach. The LTC principles characterised in the work of the community matrons reflects many of the recommendations in current Department of Health policy documents relating to the management of LTCs (Department of Health 2005a, $2006,2007)$ and provide an alternative web of causal structural relationships focused on integrated patient-centred care pathways. However, our findings indicate that it was the community matrons who had to work the hardest to establish their 
legitimacy in the local health community and who lacked championship by powerful professional colleagues. The model was championed by the community matrons themselves, and the pressure to deliver observable results such as reductions in hospital re-admission rates was immense. In this context it is unsurprising that at the time of data collection the community matron services were experiencing the most disruption and had the most difficulty engaging in the research. The theoretical whole systems perspective used in this paper anticipates the marginalisation of services which are not grounded in the deep-rooted historical causal structures.

Similarly the difficulties patients experienced in getting health care practitioners to engage in the management of co- and multi-morbidity is again reflective of the underlying causal structural relationships governing care provision. Again community matrons were the group of practitioners most likely to address the management of co-morbidity with patients, and like the community matron role the management of co-morbidity remains marginalised within the prevailing causal structural relationships.

There is considerable evidence of patient self-management and patient expertise particularly in relation to integrating the different treatment regimes for co- and multi-morbidity (Morris et al. 2011) but little evidence or data on how effective patients are at doing this or how much more effective they could be if all of their health care needs were integrated within an expert system (Tinetti et al. 2004). Developing services to support the management of co- and multi-morbidity remains a considerable challenge (Wellard et al.2007).

\section{Discussion}


Confronted with the predicted increases in demand for health care Wagner and his colleagues have developed the chronic care model (CCM) (Bodenheimer et al. 2002).This consists of four key platforms: self-management support, delivery system design, decision support, clinical information systems designed to create prepared proactive practice teams working with informed activated patients. This model is mirrored nationally in the UK by a series of policy developments introduced to enhance the role of primary care and public health (Department of Health 2005a, 2006, 2007). The data, presented here, indicate that nurses are making a contribution to meeting these policy developments replicating many of the key aspects of the CCM. However, their contribution is demarcated by the historical and structural context of health care delivery which shapes nursing practice placing structural constraints on the extent to which the potential of nursing can be realised within the current set of power relations. The scope of the nursing roles and services studied were opportunistic and reactive, frequently built around personalities and local champions, rather than planned and commissioned on an analysis of local population need. Care was organised around diagnostic categories and the needs of the service especially the Quality Outcomes Framework (QOF), rather than the integrated needs of the patient. The exception to this was the community matron services, however in these services there was little evidence of championship by local medical leaders, consequently community matrons struggled to integrate their provision with the organisation and structure of the wider health care community (Drennan et al. 2011). In each model individual nurses frequently managed to navigate beyond these constraints, helping patients to develop the capacity to selfcare (Kralik et al. 2010), but when they did it often reflected the determination of an individual practitioner and the sustainability and reproducibility of the practice beyond that individual was questioned. 
Our findings also suggest that nursing autonomy is crucially dependent on championship by local medical leaders within the prevailing structural power relationships. Community matrons while granted autonomy in the design of their role, experienced considerable difficulty in gaining legitimacy and support from the wider multi-disciplinary team and even more difficulty in asserting an alternative set of causal relationships based on patient-centred integrated care.

\section{Conclusion}

The study found considerable overlap between the expertise and effective behaviours of primary care nurses, hospital based nurse specialists and community matrons suggesting that for nursing the traditional distinction between hospital care and primary care, maybe misleading. Reducing reliance on secondary care (Department of Health 2005a, Department of Health 2009) might be better understood in a nursing context as reducing reliance on emergency and in-patient facilities. This is supported by Leary and Oliver (2010) who found that hospital based rheumatology nurse specialists recorded $51 \%$ of their work as outpatient work. Where hospital based nurse specialists had embraced patient self-management they had been extremely successful in building patient education and multi-disciplinary support services spanning primary and secondary care.

The study is limited by the difficulties in accessing practitioners in CM1 and patients in CM2. The case studies were selected because they met key policy drivers for the implementation of nurse-led LTC services in some cases pioneering new approaches to LTC. They covered a cross-section of diagnosis. They do not, therefore, represent the mainstream provision of nursing services and it is possible that there are integrated services provided by nurses that we did not access in our sampling frame. 
Improving sampling frames for case study research would be a welcome development. The patient data, however, illustrate that despite exemplary clinical expertise on the part of the nursing services, the experience of patients with a range of different conditions was remarkably similar and remains rooted in a disease orientated, fragmented model of care. Changing care models for patients requires a systemic rather than individualistic approach to service development (Wilson et al. 2012).

Despite these limitations the findings indicate that nurses are contributing to the strategic aims for managing long term conditions. The nurses in this study demonstrated their ability to implement both supported self-care and disease management according to patient need. The findings reinforce the repeated calls for and recognition that there maybe considerable efficiencies in replacing diseaseorientated care with person-orientated care (Starfield 2011, Ham and Oldham 2009) and in eliminating the distinction between primary care nursing and hospital based nurse specialists working out into the community. Key to this is the design of person-orientated information, management and funding systems for nursing caseloads (Leary et al. 2008), enabling an appropriate context for nurses to support genuine patient expertise in living with LTCs (Thorne 2008, Kralik et al. 2010). However, achieving structural change such as that recommended by Starfield (2011) and Ham and Oldham (2009) requires a much more explicit critique of the power of current causal relationships to curtail the implementation of alternative structural causal processes. 
This project was funded by the National Institute for Health Research Health Services and Delivery and Organisation (now NIHR HS\&DR) programme (project number 08/1605/121). Visit the HS\&DR website for more information. The views and opinions expressed therein are those of the authors and do not necessarily reflect those of the HS\&DR programme, NIHR, NHS or the Department of Health

\section{References}

Berzins, K., Reilly, S., Abell, J., Hughes J., Challis, D., 2009. UK self-care support initiatives for older patients with long-term conditions: a review. Chronic Illness 5 (1), 56-72.

Boaden, R, Dusheiko, M., Gravelle, H., Parker, S., Pickard, S., Roland, M, Sargent, P., Sheaff, R., 2006. Evercare Evaluation: Final Report. National Primary Care Research and Development Centre, University of Manchester, UK.

Bodenheimer, T., Wagner, E.H., Grumbach, K., 2002. Improving primary care for patients with chronic illness. Journal of the American Medical Association 288 (15), 1775-1779

Bodenheimer, T., MacGregor, K, Stothart, N., 2005. Nurses as leaders in chronic care. British Medical Journal 330, 612-613

Boyatizis, R.E.,1998. Transforming qualitative information: thematic analysis and code development. Sage, California. 
Browne, G., Kingston, D., Grdisa, V., Markle-Reid, M., 2007. Conceptualisation and measurement of integrated human service networks for evaluation. International Journal of Integrated Care 7, 1568-4156.

Carey, G.E., 2010. Investigating the health implications of social policy initiatives at the local level: study design and methods. Biomedical Central Public Health 10, 759 http://www.biomedcentral.com/1471-2458/10/759

Dose Adjustment for Normal Eating (DAFNE) Study Group., 2002. Training in flexible, intensive insulin management to enable dietary freedom in people with type 1 diabetes: dose adjustment for normal eating (DAFNE) randomised controlled trial. British Medical Journal 325, 746-752.

Department of Health., 2001. The expert patient - a new approach to chronic disease management for the 21st Century. Department of Health, London.

Department of Health., 2004a. Improving chronic disease management. Department of Health, London..

Department of Health., 2004b. The configuring hospitals evidence file part one and two. Department of Health, London.

Department of Health. 2004c. Delivering investment in general practice : implementing the new GMS contract. Department of Health, London. 
Department of Health., 2005a. Supporting People with Long Term Conditions. A National Health Service and social care model to support local innovation and integration. Department of Health, London.

Department of Health., 2005b. National Service Framework for Long-term Conditions. Department of Health, London.

Department of Health., 2005c. Self-care a real choice, self-care support a practical option. Improving Care Improving Lives. Department of Health, London.

Department of Health., 2006. Caring for people with long term conditions: an education framework for community matrons and case managers. Department of Health, Leeds.

Department of Health., 2007. Raising the profile of long term conditions care. A compendium of information. Department of Health, London.

Department of Health 2008. National Health Service next stage review. Our vision for primary and community care. Department of Health, London.

Department of Health 2009. Transforming community services. Department of Health, London.

Department of Health., 2011. Millions of patients set to benefit from a modern NHS. http://www.dh.gov.uk/en/MediaCentre/Pressreleases/DH_125042 accessed 23/6/11 Drennan, V., Goodman, C., Manthorpe, J., Davies, S., Scott, C., Gage, H., Iliffe, S., 2011. Establishing new nursing roles: A case study of the English community matron initiative. Journal of Clinical Nursing 20 (19-20), 2948-2957 
Egton Medical Information Systems., 2011. A detailed description of EMIS web. http://www.emis-online.com/emis-web accessed July 2012.

Grange, M., 2011. How community matrons perceive their effectiveness in case management. Nursing Older People 23 (5), 24-9.

Gravelle, H., Dusheiko, M., Sheaff, R., Sargent, P., Boaden, R., Pickard, S., et al. 2007. Impact of case management (Evercare) on frail elderly patients: controlled before and after analysis of quantitative outcome data. British Medical Journal 334, 31-34.

Ham, C., Oldham, J., 2009. Integrating Health and Social Care in England: lessons from early adopters and implications for policy. Journal of Integrated Care 17 (6), 39.

Harwood, R.H., Sayer, A.A., Hirschfeld, M., 2004. Current and future worldwide prevalence of dependency, its relationship to total population, and dependency ratios. Bulletin of the World Health Organization 82 (4), 251-258.

Kane, R., Keckhafer, G., Flood, S, Bershadsky, B., Siadaty, M.S., 2003. The effect of Evercare on hospital use. Journal of the American Geriatrics Society 51 (10), 14271434.

Kendall, S., Wilson, P., Procter, S., Brooks, F., Bunn, F., McNeilly, E., 2010. The Nursing Contribution to Models of Chronic Disease Management. Report to NIHR Service Delivery and Organisation Programme, England.

http://www.netscc.ac.uk/hsdr/projdetails. php?ref=08-1605-121 
Kendrick, S., Conway, M., 2003. Increasing emergency admissions among older people in Scotland: a whole systems account. Information and Statistics Division: NHS Scotland.

Kralik, D., Price, K., Telford, K., 2010. The meaning of self-care for people with chronic illness. Journal of Nursing and Healthcare of Chronic Illness: An International Journal 2 (3), 197-204.

Kuper, A., Lingard, L., Levinson, W., 2008. Critically appraising qualitative research. British Medical Journal 337, 687-689.

Leary, A., Crouch, H., Lezard, A., Rawcliffe, C., Boden, L., Richardson, A., 2008. Dimensions of clinical nurse specialist work in the UK. Nursing Standard 23 (15), 4044

Leary, A., Oliver, S., 2010. Clinical Nurse specialist: adding value to care: An executive summary. Royal College of Nursing, London.

Marinetto, M., 1999. Studies of the policy process: a case analysis. Prentice Hall, London.

McHugh, G.A., Horne, M., Chalmers, K.I., Luker, K.A., 2009. Specialist community nurses: a critical analysis of their role in the management of Long-Term Conditions International Journal of Environmental. Research and Public Health 6 (10), 25502567. 
Morris, R.L., Sanders, C., Kennedy, A.P., Rogers, A., 2011. Shifting priorities in multimorbidity: a longitudinal qualitative study of patient's prioritization of multiple conditions. Chronic Illness 7(2), 147-161

Rogers, A., Bower, P., Gardner, C., Gately, C., Kennedy, A., Lee, V., Middleton, E., Reeves, D., Richardson, G., 2006. The National Evaluation of the Pilot Phase of the Expert Patient Programme. Final Report. National Primary Care Research \& Development Centre, Manchester University.

http://www.medicine.manchester.ac.uk/primarycare/npcrdcarchive/Publications/EPP\%20FINAL\%20REPORT\%202007.pdf

Sargent, P., Pickard, S., Sheaff, R., Boaden, R., 2007. Patient and carer perceptions of case management for long-term conditions Health and Social Care in the Community $15(6), 511-519$

Senge, P.M., 1990. The fifth discipline: the art and practice of the learning organization. Doubleday, New York.

Starfield, B., 2011. Challenges to primary care from co- and multi-morbidity, editorial, Primary Health Care Research and Development 12, 1-2

Thorne, S., 2008. Chronic disease management: What is the concept? Canadian Journal of Nursing Research 40 (3), 7-14.

Tinetti, M.E., Bogardus, S.T., Jr, Agostini, J.V., 2004. Potential pitfalls of diseasespecific guidelines for patients with multiple conditions. New England Journal of Medicine 351(27), 2870-4. 
Wagner, E.H., 1998. Chronic disease management: What will it take to improve care for chronic illness? Effective Clinical Practice 1, 2-4.

Wagner, E.H., Groves, T., 2002. Care for chronic diseases. British Medical Journal $325,913-914$.

Wanless, D., 2002. Securing our future health: taking a long-term view: final report. HM Treasury, London.

Wellard, S., Cox, H., Bhujoharry, C., 2007. Issues in the provision of nursing care to people undergoing cardiac surgery who also have type 2 diabetes. International Journal of Nursing Practice 13(4), 222-228

Wilson, P.M., Kendall, S., Brooks, F., 2006. Nurses' responses to expert patients: the rhetoric and reality of self-management in long-term conditions: a grounded theory study. International Journal of Nursing Studies 43, 803-818.

Wilson, P.M., 2008. The UK expert patients program: lessons learned and implications for cancer survivors' self-care support programs. Journal of Cancer Survivorship 2, 45-52.

Wilson, P.M., Brooks, F., Procter, S., Kendall, S., 2012. The nursing contribution to chronic disease management: A case of public expectation? Qualitative findings from a multiple case study design in England and Wales. International Journal of Nursing Studies 49 (1), 2-14.

World Health Organization., 2002. Innovative Care for Chronic Conditions. World Health Organization, Geneva. 
Yin, R.K., 2003a. Case study research: design and methods. 3rd ed. Sage, London.

Yin, R.K., 2003b. Applications of case study research. 2nd ed. Sage, London. 
Fig 1: Department of Health of Health NHS and Social Care LTC Model (10)

Tho NHS and Soclal Caro Long Torm Condltons Modol

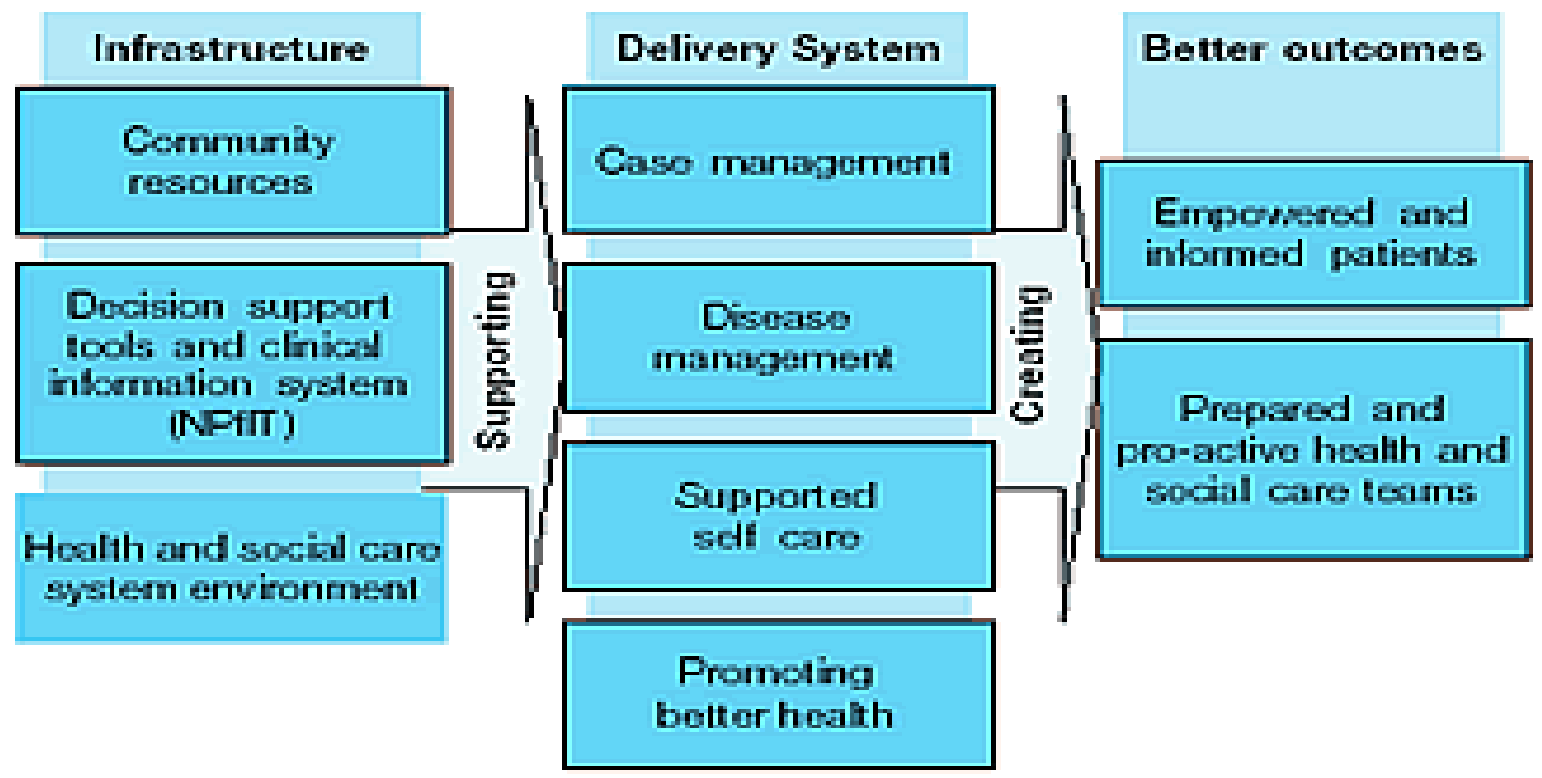


Table 1- overview of case-study sites and respondent numbers per site

\begin{tabular}{|c|c|c|c|c|c|c|}
\hline \multirow{3}{*}{$\begin{array}{l}\text { Service } \\
\text { Delivery } \\
\text { System }\end{array}$} & \multirow[t]{3}{*}{ Site } & \multicolumn{5}{|c|}{ Number Interviewed } \\
\hline & & \multirow[t]{2}{*}{ Patients } & \multirow[t]{2}{*}{ Carers } & \multicolumn{3}{|c|}{ Health Professionals } \\
\hline & & & & Nurses & Doctors & Others \\
\hline \multirow[t]{2}{*}{$\begin{array}{l}\text { Supported } \\
\text { Self-Care }\end{array}$} & $\begin{array}{l}\text { PCN1 } \\
\text { Primary Care } \\
\text { Nursing }\end{array}$ & 17 & 2 & 3 & 1 & 4 \\
\hline & $\begin{array}{l}\text { PCN2 } \\
\text { Primary Care } \\
\text { Nursing }\end{array}$ & 13 & 2 & 5 & 1 & 2 \\
\hline \multirow[t]{2}{*}{$\begin{array}{l}\text { Disease } \\
\text { Management }\end{array}$} & $\begin{array}{l}\text { NS1 } \\
\text { Clinical Nurse } \\
\text { Specialist }\end{array}$ & 17 & 4 & 4 & 2 & 1 \\
\hline & $\begin{array}{l}\text { NS2 } \\
\text { Clinical Nurse } \\
\text { Specialist }\end{array}$ & 11 & 3 & 4 & 1 & 5 \\
\hline \multirow[t]{2}{*}{$\begin{array}{l}\text { Case } \\
\text { Management }\end{array}$} & $\begin{array}{l}\text { CM1 } \\
\text { Community } \\
\text { Matron }\end{array}$ & 6 & 2 & 0 & 0 & 0 \\
\hline & $\begin{array}{l}\text { CM2 } \\
\text { Community } \\
\text { Matron }\end{array}$ & 0 & 0 & 5 & 0 & 2 \\
\hline
\end{tabular}


